\title{
Low-temperature fabrication and characterization of Ge-on-insulator structures
}

\author{
C.-Y. Yu, C.-Y. Lee, and C.-H. Lin \\ Department of Electrical Engineering, National Taiwan University, Taipei, Taiwan 106, Republic of China \\ and Graduate Institute of Electronics Engineering, National Taiwan University, Taipei, Taiwan 106, \\ Republic of China \\ C. W. Liu ${ }^{a)}$ \\ Department of Electrical Engineering, National Taiwan University, Taipei, Taiwan 106, Republic of China \\ and Graduate Institute of Electronics Engineering, National Taiwan University, Taipei, Taiwan 106, \\ Republic of China and National Nano Device Laboratories, Hsiuchu, Taiwan, R.O.C.
}

(Received 19 December 2005; accepted 22 July 2006; published online 7 September 2006)

\begin{abstract}
Ge-on-insulator structures have been fabricated by wafer bonding and layer transfer techniques. Ultralow bonding temperatures of $150-300{ }^{\circ} \mathrm{C}$ are employed in order to suppress hydrogen outdiffusion and to produce a low defect density, in an attempt to produce high photocurrent and photoresponse. Thus reducing the hydrogen outdiffusion results in decreased surface roughness. A low defect density is suggested by a low inversion-current leakage of the tunnel diodes. The photoresponse of the Ge-on-insulator detector is also found to increase with decreasing bonding temperature, indicating that defects caused by hydrogen implantation are passivated more effectively. () 2006 American Institute of Physics. [DOI: 10.1063/1.2347116]
\end{abstract}

As channel lengths of metal-oxide-semiconductor fieldeffect transistors (MOSFETs) are deeply scaling down, carrier mobility enhancement in the channel is desired for improving the performance of circuitry. To achieve this purpose, germanium $(\mathrm{Ge})$ is a promising channel material for MOSFETs because it has high electron and hole mobilities as compared with $\mathrm{Si}^{1-3}{ }^{1-3} \mathrm{~A}$ Si-on-insulator structure can improve the performance of complementary metal-oxide semiconductor circuits, due to the reduction of parasitic capacitance. Ge-on-insulator (GOI) structures may thus be particularly suitable for obtaining high-performance MOSFET devices benefiting from both the advantages of mobility enhancement and low parasitic capacitance. ${ }^{4,5}$ The layer transfer technique using wafer bonding and hydrogen implantation (also called smart cut $^{6,7}$ ) enables the fabrication of GOI structures. Recently, a GOI structure fabricated by a smartcut process with low thermal budget $\left(\sim 400{ }^{\circ} \mathrm{C}\right)$ has been reported. ${ }^{8}$ In this letter, the fabrication of GOI structures has been demonstrated at $\sim 150^{\circ} \mathrm{C}$ : so far, a lowest GOI process temperature that has been reported. Effects of hydrogen on low-temperature GOI fabrication process have several advantages with smoother cleaved surface and defect passivation beside the low mismatch of thermal expansion reported previously. ${ }^{9}$

The basic fabrication process of GOI metel-insulatorsemiconductor (MIS) detector involves hydrogen ion implantation and direct wafer bonding techniques. The $\mathrm{Sb}$ doped $n$-type Ge substrate (001) is prepared as a "host" wafer. Then, hydrogen ions with a dose of $1 \times 10^{17} \mathrm{~cm}^{-2}$ and an energy of $200 \mathrm{keV}$ are implanted into the host Ge wafer before bonding to form a deep weakened layer. On the other substrate, thermal oxide with a thickness of $80 \mathrm{~nm}$ is grown on the p-type Si substrate to form a "handle" wafer. The handle wafer and the host wafer were hydrophilicly cleaned

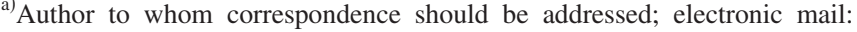
chee@cc.ee.ntu.edu.tw
}

by using $\mathrm{NH}_{4} \mathrm{OH}: \mathrm{H}_{2} \mathrm{O}_{2}: \mathrm{H}_{2} \mathrm{O}$ solution and $\mathrm{KOH}: \mathrm{H}_{2} \mathrm{O}$ solution, respectively. Then, both wafers were rinsed in deionized water and initially bonded at room temperature. ${ }^{10,11}$ The wafer pair was annealed to strengthen the chemical bonds between the two faces and to induce layer transfer along the weakened hydrogen-implanted region by $\mathrm{H}_{2}$ blistering. Metal/oxide/Ge tunneling diodes were fabricated for electrical measurements. Low-temperature $\left(\sim 50^{\circ} \mathrm{C}\right.$, lower than the bonding temperature) liquid phase deposition (LPD) was used to deposit the gate oxide; this process has the advantages of low cost, selective growth, and high throughput. The thickness of the LPD oxide was $\sim 1.6 \mathrm{~nm}$. Platinum (Pt) as a gate electrode was evaporated on the LPD oxide and large aluminum $(\mathrm{Al})$ pad as an Ohmic contact electrode was evaporated on the same side. A cross-sectional transmission electron micrograph of a GOI metal/oxide/Ge diode is shown in Fig. 1.

The hydrogen can diffuse out from the surface during the bonding process, especially at the instant of breakage. According to published experimental result, ${ }^{12}$ hydrogen is a fast diffuser in Ge. A lower process temperature produces a more concentrated hydrogen profile because of the low diffusion coefficient of hydrogen at low temperature. The concentrated hydrogen region would lead to a smooth cleaved surface since the separation along the microcavity plane during the smart-cut process is generated by the hydrogen bubbling near the peak implantation region. Figure 2 shows the surface roughness of the GOI sample as a function of process temperatures, measured by atomic force microscopy (AFM) on $1 \times 1 \mu \mathrm{m}^{2}$ area. The surface roughness continues to decrease with decreasing process temperature. A root-meansquare (rms) roughness of $\sim 7 \mathrm{~nm}$ is obtained after the $\mathrm{H}_{2}$ blistering at $150{ }^{\circ} \mathrm{C}$ for $12 \mathrm{~h}$, while the rms roughness is as high as $\sim 27 \mathrm{~nm}$ after blistering at $300{ }^{\circ} \mathrm{C}$ for the same time.

During thermal treatment, the implanted hydrogen ions can passivate the defects generated by implantation damage in the Ge. At a lower bonding temperature, the outdiffusion 


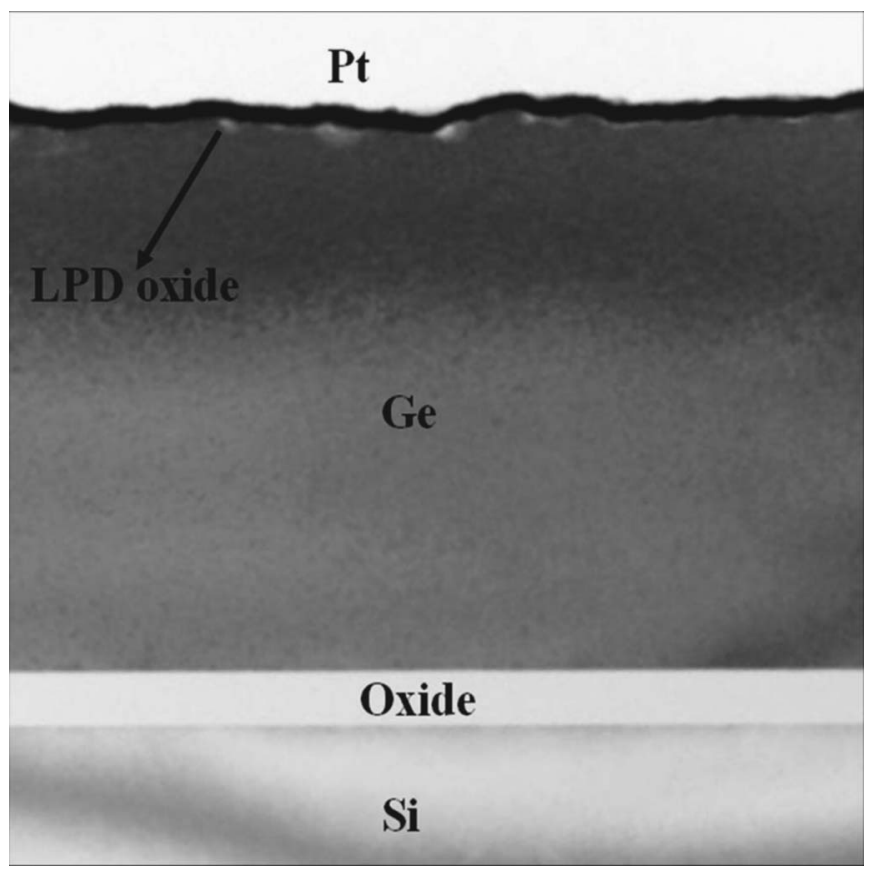

FIG. 1. Cross-sectional transmission electron micrograph of GOI MIS detector.

of hydrogen ions from the wafers can be suppressed and more hydrogen can passivate the defects. Figure 3 shows the tunneling current of Pt/oxide/GOI (MIS) diodes as a function of processing temperature. The inset of Fig. 3 is a typical current-voltage curve, for the GOI diode fabricated at $150{ }^{\circ} \mathrm{C}$. A drop in leakage current was observed for a bonding temperature of $150^{\circ} \mathrm{C}$. The leakage current of MIS tunneling diodes at inversion bias (negative bias for $n$-type $\mathrm{Ge}$ ) is dominated by thermal generation of electron-hole pairs through defects in the depletion region and at the Ge/oxide interface (Fig. 4) ${ }^{13}$ The lower defect density for the $150{ }^{\circ} \mathrm{C}$ bonding temperature is probably due to the hydrogen passivation of defects generated by hydrogen implantation. The wafer holder was cooled down to $-20^{\circ} \mathrm{C}$ during the implantation process. The heating due to the ion implantation may increase the wafer temperature, but the Ge substrate tempera-

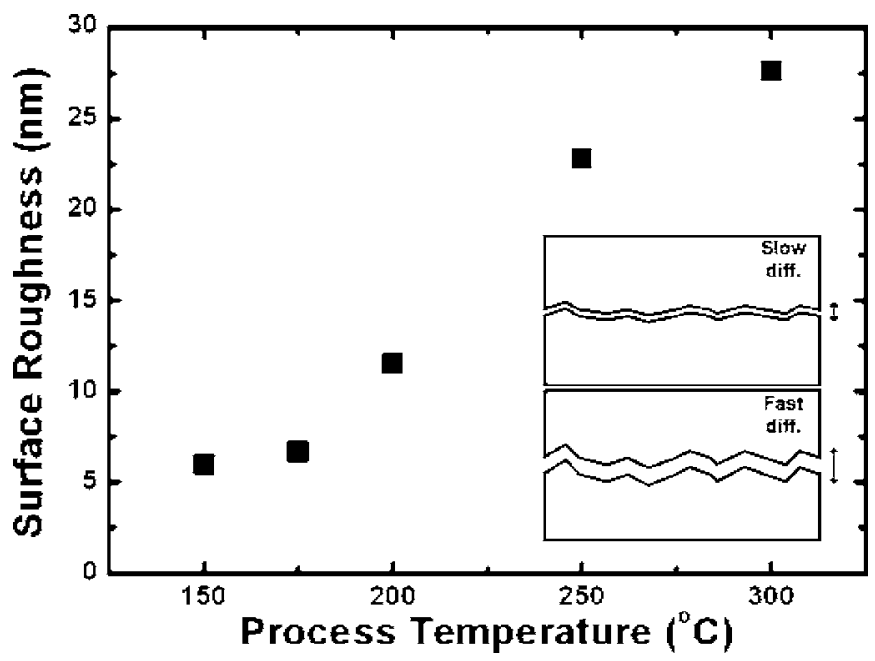

FIG. 2. Surface roughness (rms) measured by AFM as a function of process temperature. The surface roughness of the Ge-on-insulator structure decreases as the process temperature decreases ( $\mathrm{rms}$ roughness $\sim 7 \mathrm{~nm}$ at

$150{ }^{\circ} \mathrm{C}$ vs $\sim 27 \mathrm{~nm}$ at $300{ }^{\circ} \mathrm{C}$ ).
Downloaded $13 \mathrm{Feb} 2009$ to 140.112 .113 .225 . Redistribution subject to AlP license or copyright; see http://apl.aip.org/apl/copyr.

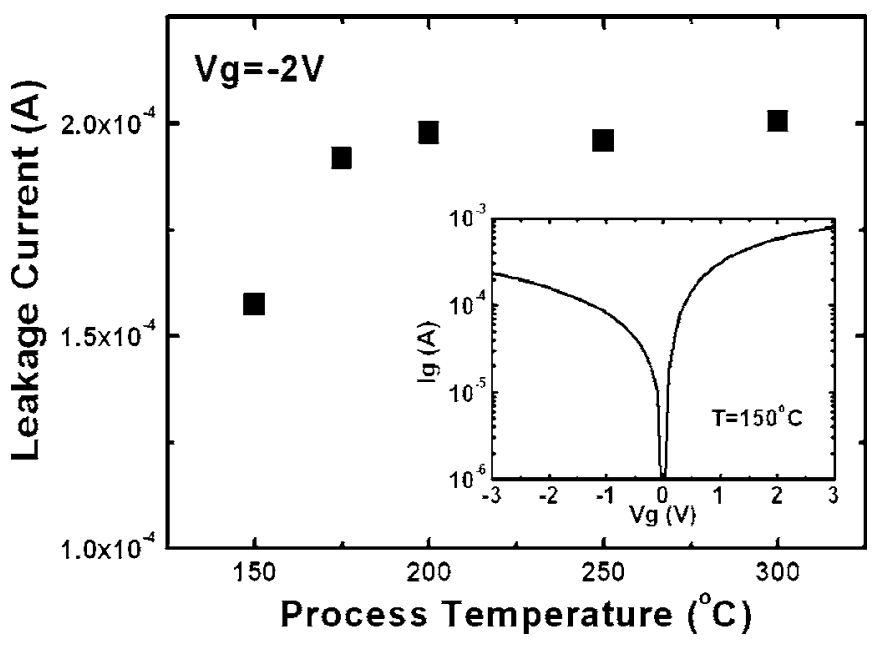

FIG. 3. Leakage current of a Pt/oxide/GOI detector with different process temperatures at inversion bias of $-2 \mathrm{~V}$. Typical current-voltage curves (inset) for the Ge-on-insulator MIS diode fabricated at $\sim 150{ }^{\circ} \mathrm{C}$.

ture is estimated to be lower than $\sim 50{ }^{\circ} \mathrm{C}$. No blistering was observed after the hydrogen implantation in the sample, indicating that the wafer temperature is low enough. Due to the equipment limit, the wafer holder temperature cannot be even lower.

Figure 5 shows the photoresponse of GOI MIS diode under light exposure at a wavelength of $850 \mathrm{~nm}$ with different bonding temperatures. ${ }^{14}$ The fiber is pointed to the edge of the gate electrode and photogenerated carriers can be collected by lateral diffusion and drift mechanisms. The photogenerated holes and electrons in the deep depletion region are separately swept towards the $\mathrm{Pt}$ and $\mathrm{Al}$ electrodes, respectively, to form the photocurrent. The responsivity increases from 3.6 to $220 \mathrm{~mA} / \mathrm{W}$ as the process temperature decreases from 300 to $150{ }^{\circ} \mathrm{C}$. Since the Ge surface is passivated by LPD oxide (the inset of Fig. 5), the surface current seems to be minimized. Surface defects in GOI near the LPD oxide can act as recombination centers, and the photogenerated electron-hole pairs can recombine at surface defects, reducing the photocurrent. Therefore, the photocurrent is more sensitive to the surface defects than the dark current. Figure 5 shows a clear trend of decreasing photocurrent with increasing bonding temperature, suggesting a concomitant

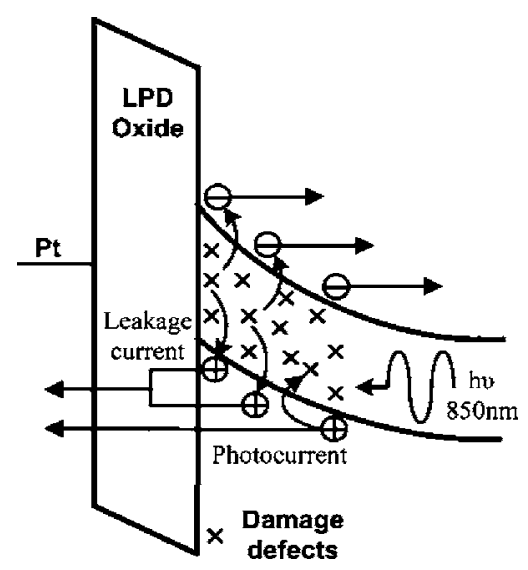

FIG. 4. Band diagram of the $n$-type GOI detector under inversion bias. The defects due to ion implantation were formed in Ge around the implanted

hydrogen profile and can act as traps to reduce the photocurrent.
to AIP license or copyright; see http://apl.aip.org/apl/copyright.jsp 


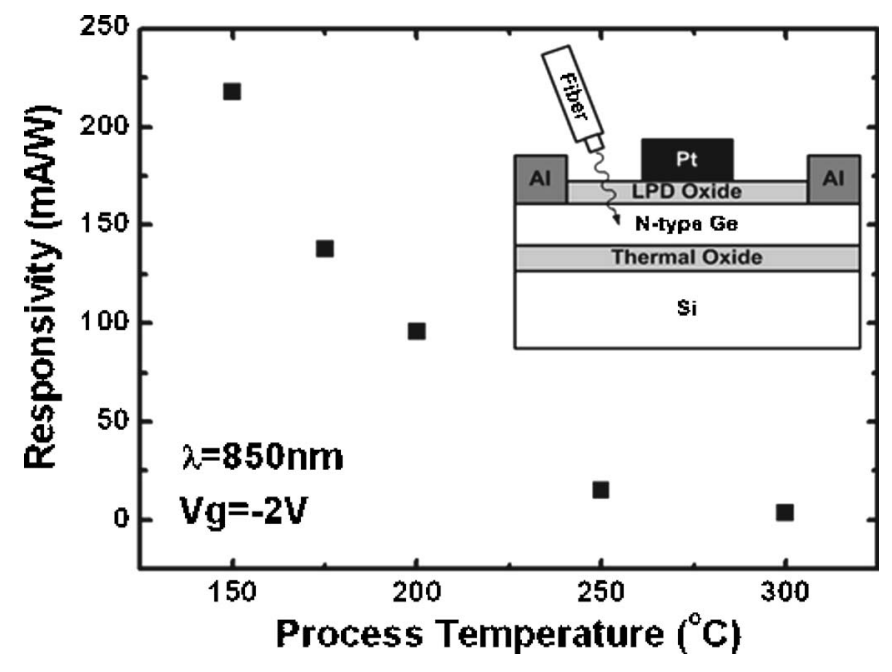

FIG. 5. Responsivity of GOI MIS detectors under light exposure at a wavelength of $850 \mathrm{~nm}$ for different process temperatures. The responsivity increases as the process temperature decreases. The inset shows the device structure of the GOI MIS detector.

increase in the surface defect density due to the release of hydrogen at high bonding temperatures.

In summary, GOI MIS detectors were fabricated by wafer bonding and layer transfer techniques at low temperatures. The surface roughness of GOI structure decreases as the process temperature decreases due to the suppression of hydrogen diffusion in the Ge, resulting in a smooth cleaved surface. The photoresponse of the GOI MIS detector is enhanced for lower bonding temperatures, due to the suppression of defects. Low-temperature bonding is thus a promis- ing technique to provide GOI wafers with low defect density for future electrical and optoelectronic applications.

This work was supported by National Science Council of ROC under Contract Nos. 94-2622-E-002-010-CC3 and 942623-7-002-020-AT, and by U.S. Air Force Office of Scientific Research/AOARD. The proof read by Dr. Temple and Dr. Maikap is highly appreciated.

${ }^{1}$ C. O. Chui, S. Ramanathan, B. B. Triplett, P. C. McIntyre, and K. C. Saraswat, IEEE Electron Device Lett. 23, 473 (2002).

${ }^{2}$ W. P. Bai, N. Lu, J. Liu, A. Ramirez, D. L. Kwong, D. Wristers, A. Ritenour, L. Lee, and D. Antoniadis, Tech. Dig. VLSI Symp. 2003, 121.

${ }^{3}$ H. Shang, H. Okorn-Schimdt, J. Ott, P. Kozlowski, S. Steen, E. C. Jones, H.-S. P. Wong, and W. Hanesch, IEEE Electron Device Lett. 24, 242 (2003).

${ }^{4}$ Y. Liu, M. D. Deal, and J. D. Plummer, Appl. Phys. Lett. 84, 2563 (2004).

${ }^{5}$ S. Takagi, Tech. Dig. VLSI Symp. 2003, 115.

${ }^{6}$ M. Burel, Electron. Lett. 37, 1201 (1995).

${ }^{7}$ Y. Cho and N. W. Cheung, Appl. Phys. Lett. 83, 3827 (2003).

${ }^{8}$ D. S. Yu, A. Chin, C. C. Liao, C. F. Lee, C. F. Cheng, M. F. Li, W. J. Yoo, and S. P. McAlister, IEEE Electron Device Lett. 26, 118 (2005).

${ }^{9}$ V. Dragoi, M. Alexe, M. Reiche, and U. Gosele, Proceedings of the IEEE International Semiconductor Conference, 5-9 October 1999, Vol. 2, p. 443.

${ }^{10}$ C.-Y. Yu, P.-W. Chen, S.-R. Jan, M.-H. Liao, K.-F. Liao, and C. W. Liu, Appl. Phys. Lett. 86, 011909 (2005).

${ }^{11}$ Q.-Y. Tong and U. Gosele, Semiconductor Wafer Bonding (Wiley, New York, 1999).

${ }^{12}$ O. Madelung, Data in Science and Technology: Semiconductors (Springer, New York, 1991).

${ }^{13}$ C.-H. Lin, B.-C. Hsu, M. H. Lee, and C. W. Liu, IEEE Trans. Electron Devices 48, 2125 (2001).

${ }^{14}$ M. H. Liao, C.-Y. Yu, C.-F. Huang, C.-H. Lin, C.-J. Lee, M.-H. Yu, S. T. Chang, C.-Y. Liang, C.-Y. Lee, T.-H. Guo, C.-C. Chang, and C. W. Liu, Tech. Dig. Ser.-Opt. Soc. Am.1001 (2005). 